\title{
ELABORATION OF THE NEW METHOD OF CONSERVING VOLATILE AROMATIC SUBSTANCES OF SPICY VEGETABLES AT CREATING HEALTHY CRYO-SUPPLEMENTS
}

\author{
Viktoriya Pogarskaya \\ Department of Technology processing of fruits, vegetables and milk \\ Kharkiv State University of Food Technology and Trade \\ 333 Klochkivska str., Kharkiv, Ukraine, 61051 \\ viktoria.pogarskaya@gmail.com

\section{Raisa Pavlyuk} \\ Department of Technology processing of fruits, vegetables and milk \\ Kharkiv State University of Food Technology and Trade \\ 333 Klochkivska str., Kharkiv, Ukraine, 61051 \\ ktppom@ukr.net

\section{Oleksander Cherevko} \\ Department of Processes, Devices and Automation of Food Production \\ Kharkiv State University of Food Technology and Trade \\ 333 Klochkivska str., Kharkiv, Ukraine, 61051

\section{Vadym Pavliuk} \\ Department of Applied Mathematics and Information Technologies
}

Kharkiv Trade and Economics Institute of Kyiv National University of Trade and Economics

8 Otakara Yarosha lane, Kharkiv, Ukraine, 61045

\section{Ludmila Radchenko}

Kharkiv Trade-Economic Colledge of Kyiv National University of Trade and Eco-nomics 202 Klochkivska str., Kharkiv, Ukraine, 61045

kharkiv@htek.com.ua

\section{Ekaterina Dudnyk}

Department of Technology processing of fruits, vegetables and milk Kharkiv State University of Food Technology and Trade 333 Klochkivska str., Kharkiv, Ukraine, 61051

\section{Tatyana Kolomiets}

Technology Department

Lipkovatovsky Agricultural College

1 Dotsenko sq., Kharkiv region., Novovodolazhsky district, Lipkovatovka village, Ukraine, 63221

\section{Anna Radchenko}

Kharkiv Trade-Economic Colledge of Kyiv National University of Trade and Eco-nomics 202 Klochkivskaya str., Kharkiv, Ukraine, 61045

kharkiv@htek.com.ua

\section{Aleksey Pogarskiy}

Department of Technology processing of fruits, vegetables and milk Kharkiv State University of Food Technology and Trade 333 Klochkivska str., Kharkiv, Ukraine, 61051 


\begin{abstract}
The aim of the work is to develop the new method of deep processing of spicy vegetables (ginger root, garlic, celery root, horseradish root) that gives a possibility to fully conserve volatile aromatic substances (ethereal oils, ketones, aldehydes, esters) and other biologically active substances (BAS) - phytocomponents of vegetable raw materials. At the same time this method gives a possibility to extract their hidden forms (bound in nanocomplexes with biopolymers, BAS) in the free soluble active form at receiving healthy semi-products (in puree form) and food products in the freely assimilated - nanosize form.

For attaining this aim, cryogenic "shock" freezing and fine-dyspersated comminution using liquid and gas-like nitrogen with the modern equipment for cryo-processing and fine-dyspersated comminution was used as an innovation.

There was developed the new method of getting healthy supplements and products of spicy vegetables (roots of ginger, celery, horseradish, garlic), cryo-processed using cryogenic liquid of liquid and gas-like nitrogen in the cryogenic fast-freezing apparatus and fine-dyspersately comminuted with the high content of aromatic phytosubstances, especially ethereal oils and other BAS, especially low-molecular phenol compounds, polyphenols, ascorbic acid and prebiotics. The new method of deep processing of spicy vegetables is based on the complex effect of processes of cryo-destruction, mechanodestruction and non-fermentative catalysis on raw materials at fine-dyspersated comminution. It was established, that at cryogenic "shock" freezing there takes place not only complete conservation of vitamins, aromatic substances, but their more complete extraction from the bound hidden form with biopolymers and BAS in the free one (1,7 ...2,5 times more that extracted from free vegetables). The quality of spicy vegetables $1,7 \ldots .2,5$ exceeds the quality of fresh vegetables and analogues.

The essentially more effect of extracting hidden forms of aromatic substances and other BAS was revealed at low-temperature fine-dyspersated comminution of cryo-processed spicy vegetables. It was demonstrated, that at fine-dyspersated comminution there takes place 1,7...3,2 times more full extraction of hidden forms of low-molecular BAS than in fresh vegetables.

Using new types of fine-dyspersated puree of spicy vegetables, there is developed the line of high-quality products for healthy nutrition with the stable texture and long storage life (juice nanodrinks, sauces-dressings, sauces-deeps, salted fillings for confectionary products, snacks, milk-vegetable products).
\end{abstract}

Keywords: cryogenic freezing, spicy vegetables, liquid nitrogen, mechanolysis, hidden forms of BAS.

DOI: $10.21303 / 2504-5695.2018 .00670$

(C) Viktoriya Pogarskaya, Raisa Pavlyuk, Oleksander Cherevko, Vadym Pavliuk, Ludmila Radchenko, Ekaterina Dudnyk, Tatyana Kolomiets, Anna Radchenko, Aleksey Pogarskiy

\title{
1. Introduction
}

The one of main sources of vegetable BAS is spicy vegetables (SV), especially, roots of celery ("golden root"), ginger, horseradish, garlic [1]. These types of SV are considerably remarkable among other types of vegetable raw materials because of the high content of aromatic substances, phenol compounds and other healing substances and are used in nutrition of the population of many countries throughout the world. Healthy properties of spicy vegetables are maximally conserved at consuming fresh. At processing and storage of spicy vegetables there take place essential losses (from 20 to $80 \%$ ) of volatile aromatic substances, phenol compounds and other BAS [2].

So, it is urgent to search for new technological methods, ways that allow to maximally conserve BAS of raw materials at developing healthy supplements and nanoproducts of spicy vegetables with the high content of aromatic substances, phenol compounds and other BAS.

According to the data of scientists of medical institutions of leading countries, unsaturated aromatic phytocomponents, low-molecular and high-molecular phenol compounds have many diverse protective regulatory functions [1]. They include purification (detoxication and removal of harmful and toxic substances from the human organism), regulation of the acid-alkaline pH-balance and level of hormones in the human organism. At the same time they are remarkable for improving the immunity and also anti-bacterial, geroprotective effect and strengthening of cardiac and cerebral vessels, blocking of free oxidative radicals in the human organism.

Spicy vegetables are traditionally consumed fresh and used as dry flavorings at cooking different meals (first dishes, meat, fish products). Among products that include spicy vegetables, sauces-dressings, sauces-deeps, snacks, drinks, marinades for meat and fish are popular among people of different countries of the world [2,3]. Despite the essential content of such unique phytocomponents as aromatic substances (ethereal oils, phenol compounds, tanning substances, phytoncides) with healing properties in the composition of spicy vegetables, they are not widely consumed in nutrition of the population. Products for mass consumption, at which manufacturing spicy vegetables are used as a main raw material, are absent. 
Complications at processing spicy vegetables using traditional thermal methods are connected with essential losses of volatile and other BAS. That is why it is urgent to search for technological methods that allow to conserve and stabilize the quality of fresh SV at their transformation in different types of supplements and food products.

The one of prospective directions of getting healthy food products of fruits and vegetables is freezing [2-4]. According to data of FAE/WHO, freezing of food products was accepted as one of most progressive methods of processing and conservation of food raw materials [1]. The most effective way of freezing that provides the highest degree of conserving vitamins and other BAS is fast "shock" freezing by the flow of cold air [3]. A disadvantage of this way of freezing after storage during 6 months is essential losses of cellular juice and vitamins at defrost $[2,4,7,8]$. Leading countries widely use gene "shock" freezing that differs from the traditional one by using cryogenic liquids (especially, liquid nitrogen, carbonic acid and so on) [9-11]. The scientific interest is that the cryogenic method of freezing provides the highest degree of conserving vitamins and other BAS. It is not widely used in Ukraine. At the same time cryogenic technologies of processing fruits and vegetables that allow to conserve BAS maximally are not developed. Physical-chemical, biochemical processes of cryodestruction, mechanodestruction at cryo-freezing fruits, vegetables and purees of them are not studied.

The task of the work is to develop the new method of deep processing of spicy vegetables that allows to get healthy nanosupplements and nanoproducts with the high content of BAS. It is based on the complex effect of cryogenic "shock" freezing and mechanolysis at fine-dyspersated comminution. The use of the method of deep processing of food raw materials at getting products of chlorinecontaining and carotene-containing raw materials and also mushrooms and leguminous, elaborated by the authors, allows to not only conserve the biological potential of fresh vegetable raw materials, but also to extract their hidden reserves $[2,4,6]$. So, there was assumed, that this method of cryoprocessing allows to conserve volatile aromatic substances and other BAS and also to extract their hidden forms in the free soluble active form at receiving healthy vegetable supplements and products.

\section{Materials and methods of research}

Fresh spicy vegetables (celery, ginger, horseradish roots, garlic) were used as research objects in the work (Fig. 1).

Selection of samples for the experiments and also their preparation for further processing were carried out according to normative documents for each type of raw materials and ready products (SSU 4837: 2007 fast frozen fruits and vegetables).

For attaining this aim, the complex effect of cryogenic "shock" freezing and non-fermentative catalysis (mechanolysis) at fine-dyspersated comminution was used as an innovation at processing spicy vegetables. At that there was used the modern equipment (combi steamer, cryogenic fast-freezing apparatus, homogenizer-comminutor) for cryo-processing and comminution for activation, destruction and extraction of inactive hidden forms of BAS in the free, soluble nanoform.

The scientific studies were carried out in Kharkov State University of Food Technology and Trade (HSUFT) at the Department of Technology processing of fruits, vegetables and milk. The experimental studies were carried out on the base of the scientific-research laboratory of "Innovative cryo- and nanotechnologies of vegetable supplements and healthy products), using the modern equipment (combi steamer, cryogenic fast-freezing apparatus, homogenizer-comminutor).

Cryogenic "shock" freezing was carried out in the fast-freezing experimental apparatus using liquid and gas-like nitrogen as a cooling agent and inert medium $[5,6]$. The apparatus is designed for freezing products with the solid cover and liquid products, placed in a special package. It allows to vary the temperature in the freezing chamber in the diapason from $-5^{\circ} \mathrm{C}$ to $-100{ }^{\circ} \mathrm{C}$. The temperature of the gas medium in the cooling chamber is fixed by hand and automatically kept constant during the whole experiment. It can be changed at any stage of the experiment if necessary. Freezing of spicy vegetables was conducted with the high speed from 0,5 to $10^{\circ} \mathrm{C}$ in a minute to the final temperatures within the product $-18{ }^{\circ} \mathrm{C},-25{ }^{\circ} \mathrm{C},-32{ }^{\circ} \mathrm{C},-35^{\circ} \mathrm{C}$. It was established experimentally, that at freezing spicy vegetables the optimal temperature in the chamber of the fast-freezing apparatus was $-60{ }^{\circ} \mathrm{C}$ that provides best results at releasing BAS from the bound form in the free one. 


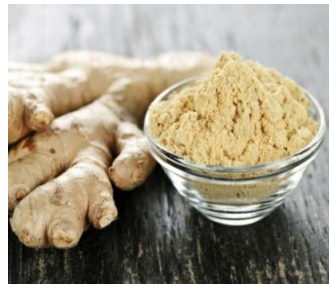

$a$

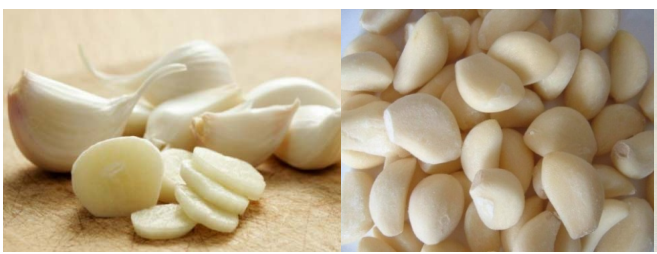

$d$

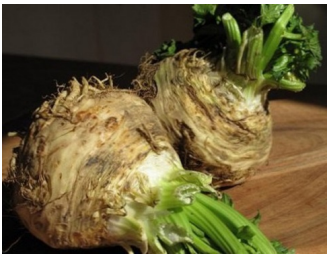

$g$

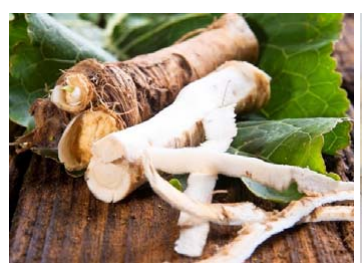

j

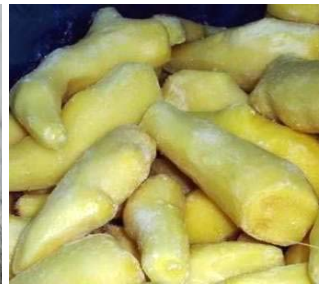

$b$

e

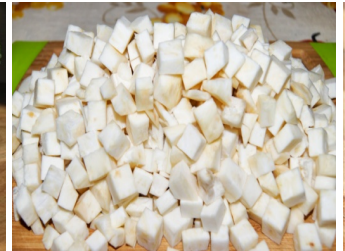

$h$

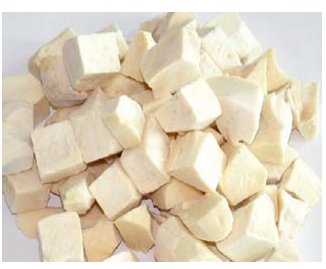

$k$

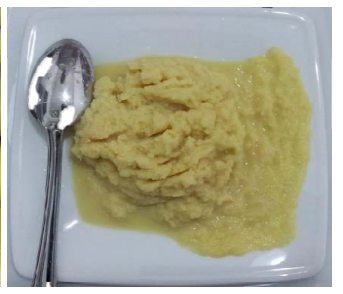

c

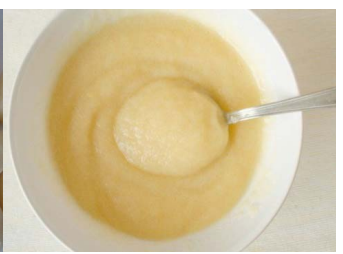

$f$

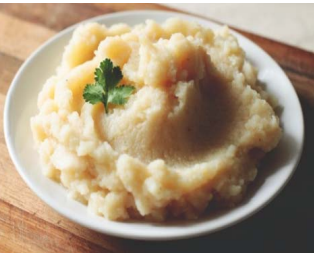

$i$

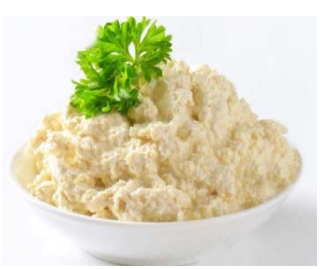

$l$

Fig. 1. Research objects: $a-c-$ ginger root fresh and rough-comminuted $(a)$, frozen (b), cryo-puree of ginger root (c); d- $f$-garlic fresh (d), frozen (e), cryo-puree of garlic (f); $g-i$ - celery root fresh $(g)$, frozen $(\mathrm{h})$, cryo-puree of celery root $(i)$; $\mathrm{j}-\mathrm{l}-$ horseradish fresh $(j)$, frozen $(\mathrm{k})$, cryo-puree of horseradish (l)

The homogenizer-comminutor Robot Couper (France) was used for fine-dyspersated comminution of spicy vegetables $[5,6]$.

Nanoproducts (sauces-dressings, sauces-deeps, snacks and fillings) with healthy supplements of spicy vegetables were manufactured by the combi steamer UNOX SPA series XVC (Italy) $[5,6]$. This equipment gives a possibility to manufacture products in their own juice without vegetable oils that allows to conserve the natural taste and nutritive substances of fresh raw materials. Depending on constructive features, the combi steamer can realize the culinary processing of products using different processing modes: by wet steam, dry heat, overheated steam, regulated steam. All these modes were used both in the complex and separately at elaborating the new method of conserving volatile aromatic substances of spicy vegetables at getting healthy cryo-supplements. Cooking of each dish in the combi steamer is realized without any external intervention, necessity for irrigation or removal of moisture by hand.

The use of this equipment allows to model technological processes for finding methods of maximal conservation of BAS in initial raw materials and extraction of hidden BAS and biopolymers of vegetable raw materials. The obtained research results were used at developing nanotechnologies for manufacturing new types of products and supplements of SV, which quality exceeds the one of initial raw materials and products and supplements - analogues by BAS content. 


\section{1. Experimental procedures}

The quality of fresh spicy vegetables (ginger root, garlic, celery root, horseradish root), cryo-frozen ones and also of frozen fine-dyspersated puree of SV was determined by BAS, especially:

- Aromatic volatile substances, controlled by the smell number by the titrometric method, included in the standard (SS 756.77) [2]. This method is based on the ability of the chrome mixture to oxidize ethereal oils. The share of aromatic substances in a product was established by the amount of spent potassium and conventionally expressed in milliliters of sodium thiosulphates for $100 \mathrm{~g}$ of a product.

- Low-molecular phenol compounds (by rutin and chlorogenic acid separately) were determined by the colorometric method of Folin-Denis in recalculation by rutin and chlorogenic acid separately. $[5,6]$ The methods were included in standards.

- L-ascorbic acid was determined by the method of visual and potentiometric titration by the solution of 2,6-Dichlorophenolindophenol $\mathrm{Na}[5,6]$.

- Tanning substances (by tannin) were determined by the titrometric method in recalculation by tannin, included in the state standard for methods of controlling the quality of food products [SS 24027.2-80]. This method is based on the ability of tanning substances to oxidize in presence of the indigo carmine indicator $[5,6]$.

- Pectin, the method is based on hydrolysis of pectin substances and precipitation of polygalacturonic acid as cellulose sodium pectate.

- Organic acids, the method is in removal of free acids with water steam and further titration by alkali. Orthophosphoric acid is used for transforming salts in free acids. The amount of titrated volatile acids is recalculated by acetic acid.

- Protein was determined by the nitrogen-metric method (Kjeldahl's method), based on determination of the amount of albuminous nitrogen, created at destruction of amino acids, included in the composition of proteins.

For controlling the aforesaid BAS and prebiotic substances, there were used chemical, physical-chemical and spectroscopic research methods. They are presented in works $[2,5,6]$.

\section{Results}

At elaborating nanotechnologies, healthy supplements of spicy vegetables and healthy nanoproducts (sauces-dressings, marinades, salads, nanosorbets, snacks, nanodrinks, fillings for confectionary products and so on) were obtained (Fig. 2).

The essential share of healthy products is recommended for both manufacturing at big enterprises of food industry and institutions of restaurant business, culinary and confectionary workshops of super-markets and also in individual nutrition of the population.

At the model experiments, it was established, that cryogenic "shock" freezing of spicy vegetables, cut in pieces, with the high speeds (from 0,5 to $10^{\circ} \mathrm{C} / \mathrm{min}$ ) to the temperature within a product $-32 \ldots-35^{\circ} \mathrm{C}$ using liquid and gas-like nitrogen provides the complete conservation of vitamins, aromatic substances, phenol compounds, polyphenols and other BAS. The use of cryo-processing favors more complete (in 1,5 .. 2,5 times) extraction of BAS of fresh spicy vegetables from the hidden form (bound with biopolymers) in the free one. The quality of frozen spicy vegetables exceeds in $1,5 \ldots 2,5$ times the quality of fresh vegetables and analogues. Hidden forms of aromatic and phenol compounds in spicy vegetables were revealed. It was demonstrated, that fine-dyspersated comminution of frozen vegetables provides 1,7...3,2 more complete extraction of hidden forms of low-molecular BAS.

Based on the experimental studies, there was elaborated the new method of cryo-processing and non-fermentative catalysis (mechanical destruction of nanocomplexes of biopolymers with low-molecular BAS) of spicy vegetables. The new method of processing SV differs from traditional ones by the almost complete exclusion of thermal processing. It is based on using the complex effect of cryogenic freezing of raw materials using "shock" freezing with liquid and gas-like nitrogen, steam-thermal processing and fine-dyspersated mechanical cominution as an innovation. The new method gives a possibility of conserving all aromatic substances and other BAS of initial raw materials and preventing destruction processes. It is a method of deep processing that allows to extract bound (hidden) forms of aromatic substances and other BAS of spicy vegetables. The later have an anti-oxidant, detoxing, immune-modeling and conserving effect and allow to get products with a brightly expressed smell. 


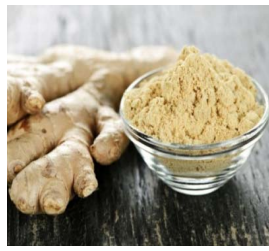

$a$

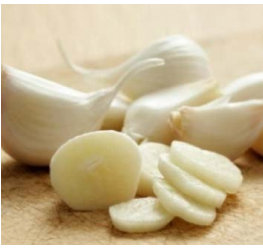

$e$

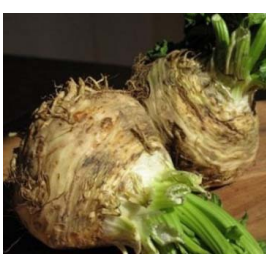

$i$

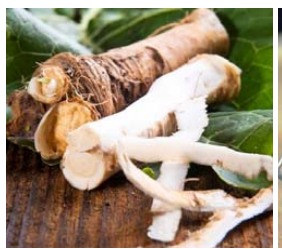

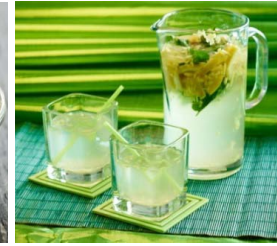

b

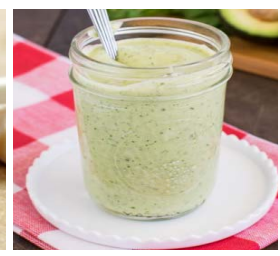

f

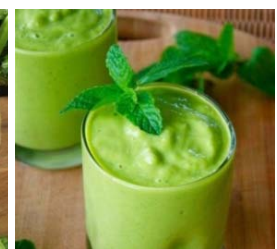

$j$

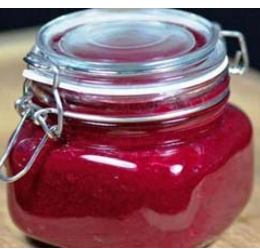

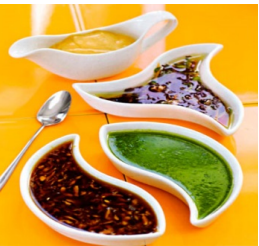

c

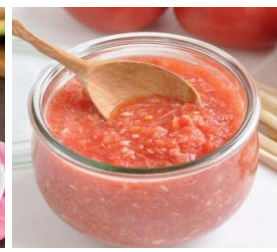

$g$

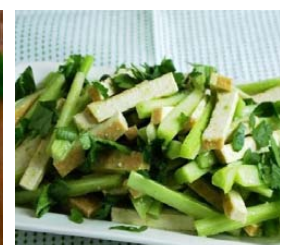

$k$
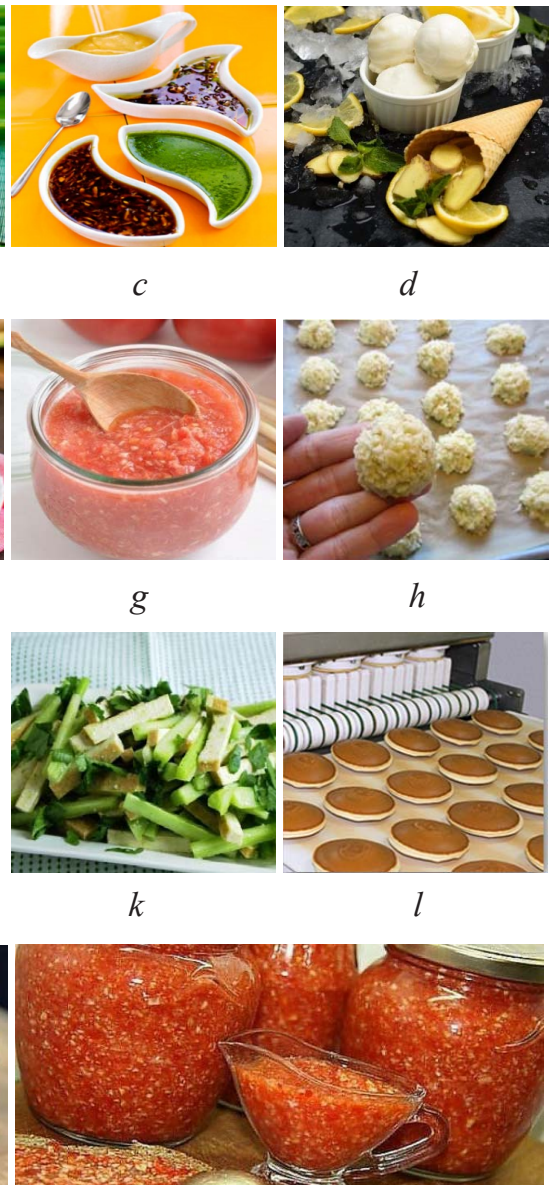

d

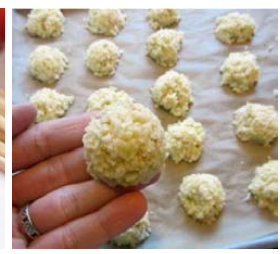

$h$

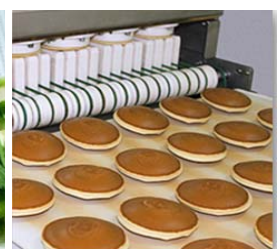

1

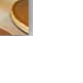


nents - phenol compounds, polyphenols and other BAS in 2..2,5 times. Hidden forms of BAS of spicy vegetables were discovered. Technological modes and technologies of healing supplements as fine-dyspersated puree of fresh and frozen spicy vegetables were elaborated. Using obtained frozen products and supplements of spicy vegetables, there was created the wide assortment of products that exceed known analogues by quality.

The obtained research results allow to consider the process of freezing fruits and vegetables and getting fine-dyspersated frozen puree of them in a new aspect. It must be noted, that each vegetable raw material - is a very complicated heterogenic fine-dyspersated system that includes up to 1000 different substances. At processing and storing fruits and vegetables, there take place complicated fermentative, biochemical, chemical and other processes that must be guided skillfully. Elaboration of nanotechnologies using cryo-processing of spicy vegetables includes innovations, special approach that form "know-how" of this method.

The new method of processing spicy vegetables allows to get cryo-purees, which quality exceeds the quality of ones, obtained by traditional methods, by the content of volatile aromatic substances and other BAS that was experimentally proved at the department of processing fruits, vegetables and milk in HSUFT, which staff is working in the field of cryogenic freezing over than 30 year $[2,5,6]$. Using frozen spicy vegetables and purees of them, there were developed different types of healthy products with the high content of natural BAS. New products exceed analogues of products, obtained by traditional processing methods by BAS content.

\section{Conclusions}

There was elaborated the new method of obtaining healthy supplements and products of spicy vegetables with the high degree of conserving volatile aromatic substances and other BAS. It is based on the complex effect of cryogenic processing of raw materials at the freezing stage using liquid and gas-like nitrogen and fine-dyspersated comminution. This way of deep processing of raw materials includes processes of cryodestruction and mechanodestruction, non-fermentative catalysis. Mechanisms of these processes are elucidated.

It was demonstrated, that at cryogenic processing of SV in the fast-freezing apparatus with high freezing speeds, there takes place not only conservation of aromatic substances, vitamins and other BAS, but their complete extraction from the hidden form in 1,5...2,5 times more than it is fixed in fresh vegetables. The quality of frozen SV exceeds fresh ones in 2,0..2,5 times by BAS content.

It was established, that the essentially more effect of extracting hidden (bound) forms of aromatic substances and other BAS in the free one takes place at fine-dyspersated comminution of $\mathrm{SV}(1,7 \ldots 3,2$ more than it is observed in fresh ones).

Using frozen spicy vegetables and purees of them, there were developed different types of healthy products with the high content of natural BAS. There were created: sauces-dressings, sauces-deeps, fillings for confectionary products, especially "Pan Cakes", nanodrinks, snacks, flavorings for meat and fish dishes, spicy supplements in nanosorbets and so on.

\section{References}

[1] The state of food safety and nutrition in the world $2017 \mathrm{WHO} / \mathrm{FAO} / \mathrm{UNU}$ (2017). Geneva: World Healt Organization, 119.

[2] Pavlyuk, R. Yu., Pogarska, V. V., Radchenko, L. O., Pavlyuk, V. A., Tauber, R. D., Tymofieieva, N. M., Bessarab O. S. et. al. (2017). Novyi napriamok hlybokoi pererobky kharchovoi syrovyny. Kharkiv: Fakt, 380 .

[3] Stringer, M., Dennis, K. (2004). Ohlazhdennye i zamorozhennye produkty. Saint Petersburg: Professiya, 492.

[4] Sinha, N. K., H'yu, I. G. (2014). Nastol'naya kniga po pererabotke plodovoovoshchnoi produkcii. Saint Petersburg: Professiya, 912.

[5] Pavlyuk, R., Pogarska, V., Mikhaylov, V., Bessarab, O., Radchenko, L., Pogarskiy, A. et. al. (2018). Development of a new method of storage and maximum separation of chlorophils from chlorophylcontaining vegetables at reception of healthfull nanoproducts. EUREKA: Life Sciences, 2, 47-54. doi: http:// doi.org/10.21303/2504-5695.2018.00616 
[6] Pogarska, V., Pavlyuk, R., Timofeyeva, N., Bilenko, L., Stukonozhenko, T. (2016). Elaboration of new method of deep processing of caro-tene-containing raw materials into nanoadditives with the use of cryogenic freezing and fine-dispersed grinding. EUREKA: Life Sciences, 6, 37-43. doi: http://doi.org/ 10.21303/2504-5695.2016.00251

[7] Tu, J., Zhang, M., Xu, B., Liu, H. (2015). Effects of different freezing methods on the quality and microstructure of lotus (Nelumbo nucifera) root. International Journal of Refrigeration, 52, 59-65. doi: http:// doi.org/10.1016/j.jijrefrig.2014.12.015

[8] Tuan Pham, Q. (2014). Freezing time formulas for foods with low moisture content, low freezing point and for cryogenic freezing. Journal of Food Engineering, 127, 85-92. doi: http://doi.org/10.1016/ j.jfoodeng.2013.12.007

[9] James, S. J., James, C. (2014). Chilling and Freezing. Food Safety Management, 481-510. doi: http://doi.org/10.1016/b978-0-12-381504-0.00020-2

[10] Evans, J. (2016). Emerging Refrigeration and Freezing Technologies for Food Preservation. Innovation and Future Trends in Food Manufacturing and Supply Chain Technologies. Woodhead Publishing, 175-201. doi: http://doi.org/10.1016/b978-1-78242-447-5.00007-1

[11] Min, K., Chen, K., Arora, R. (2014). Effect of short-term versus prolonged freezing on freezethaw injury and post-thaw recovery in spinach: Importance in laboratory freeze-thaw protocols. Environmental and Experimental Botany, 106, 124-131. doi: http://doi.org/10.1016/j.envexpbot.2014.01.009

\title{
INVESTIGATIONS OF THE FUNCTIONAL AND TECHNOLOGICAL PROPERTIES OF DOUGH SEMI- PRODUCTS ENRICHED WITH DIETARY SUPPLEMENTS
}

\author{
Tatyana Golovko
}

Department of commodity research in customs business Kharkiv State University of Food Technology and Trade 333 Klochkivska str., Kharkiv, Ukraine, 61051 golovko.tatyana.10@gmail.com

Micola Pogozhikh

Department of physical and mathematical and engineering-technical disciplines Kharkiv State University of Food Technology and Trade 333 Klochkivska str., Kharkiv, Ukraine, 61051 m.pogozhikh@hduht.edu.ua

\section{Andrey Pak}

Department of physical and mathematical and engineering-technical disciplines Kharkiv State University of Food Technology and Trade 333 Klochkivska str., Kharkiv, Ukraine, 61051 a.pak@hduht.edu.ua

\section{Nicolay Golovko}

Department of commodity research in customs business Kharkiv State University of Food Technology and Trade 333 Klochkivska str., Kharkiv, Ukraine, 61051 golovko.m.p@ukr.net

\section{Alina Pak}

Department of merchandising and examining the quality of goods Kharkiv Institute of Trade and Economics of Kyiv National University of Trade and Economics 8 Otakara Yarosha str., Kharkiv, Ukraine, 61045 pak.alina1984@gmail.com 